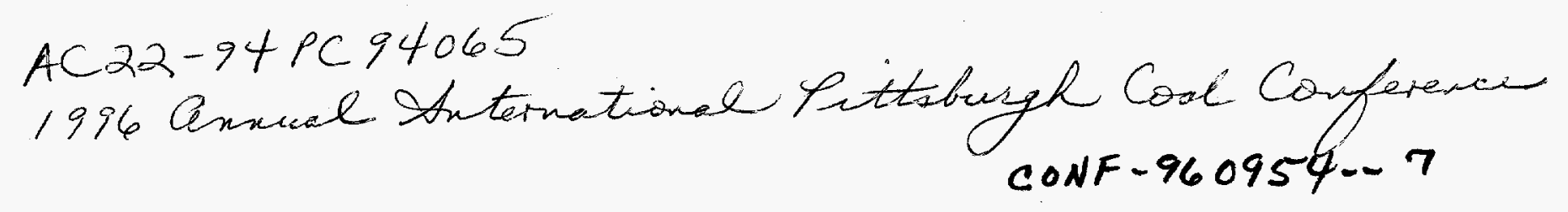

\title{
ACID-BASE PROPERTIES, DEACTIVATION, AND IN SITU REGENERATION OF CONDENSATION CATALYSTS FOR SYNTHESIS OF METHYL METHACRYLATE
}

\author{
MAKARAND R. GOGATE ${ }^{1}$, JAMES J. SPIVEY ${ }^{1}$, \\ AND JOSEPH R. ZOELLER ${ }^{2}$ \\ ${ }^{1}$ Research Triangle Institute, 3040 Cornwallis Road, RTP, NC 27709-2194 \\ ${ }^{2}$ Eastman Chemical Company, Kingsport, TN, 37662-5150
}

\begin{abstract}
Condensation reaction of a propionate with formaldehyde is a novel route for synthesis of methyl methacrylate (MMA). The reaction mechanism involves a proton abstraction from the propionate on the basic sites and activation of the aliphatic aldehyde on the acidic sites of the catalyst. The acid-base properties of ternary V-Si-P oxide catalysts and their relation to the MMA yield in the vapor phase condensation of formaldehyde with propionic anhydride has been studied for the first time. Five different V-Si-P catalysts with different atomic ratios of vanadium, silicon, and phosphorous were synthesized, characterized, and tested in a fixed-bed microreactor system. A V-Si-P 1:10:2.8 catalyst gave the maximum condensation yield of $56 \%$ based on HCHO fed at $300{ }^{\circ} \mathrm{C}$ and $2 \mathrm{~atm}$ and at a space velocity of $290 \mathrm{cc} / \mathrm{g}$ cat h. A parameter called the "q-ratio" has been defined to correlate the condensation yields to the acid-base properties. The correlation of q-ratio with the condensation yield shows that higher q-ratios are more desirable. The long-term deactivation studies on the V-Si-P $1: 10: 2.8$ catalyst at $300^{\circ} \mathrm{C}$ and 2 atm and at a space velocity of $290 \mathrm{cc} / \mathrm{g}$ cath show that the catalyst activity drops by a factor of nearly 20 over a $180 \mathrm{~h}$ period. The activity can be restored to about $78 \%$ of the initial activity by a mild oxidative regeneration at $300{ }^{\circ} \mathrm{C}$ and $2 \mathrm{~atm}$. The performance of $\mathrm{V}-\mathrm{Si}-\mathrm{P}$ catalyst has been compared to a $\mathrm{Ta} / \mathrm{SiO}_{2}$ catalyst. The Ta-catalyst is more stable and has a higher on-stream catalyst life.
\end{abstract}

\section{INTRODUCTION}

The most widely used technology for the manufacture of methyl methacrylate (MMA) to date is the acetone cyanohydrin process [1]. More than $85 \%$ of the MMA made in the world uses this technology [2]. However, the acetone-cyanohydrin $(\mathrm{ACH})$ process involves the use of the toxic $\mathrm{HCN}$ and produces copious quantities of ammonium bisulfate wastes. Environmental pressures against shipment of HCN have forced many producers away from byproduct $\mathrm{HCN}$ (from acrylonitrile manufacture) in favor of on-site synthesis from methane and ammonia. It is difficult to dispose of spent sulfuric acid and ammonium bisulfate waste which has often led to very

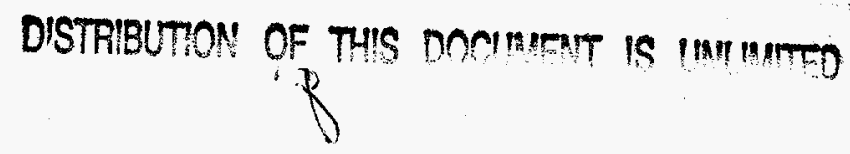




\section{DISCLAIMER}

Portions of this document may be illegible in electronic image products. Images are produced from the best available original document. 
expensive thermal recovery units. This has led to substantial increases in the cost of MMA manufacture. The ACH technology is environmentally and economically untenable for any new expansions.

There is a strong drive within the chemical industry for a replacement process. In the United States and abroad, there is a particular interest in the process that is not petroleum based is based on domestically produced coal-based syngas. The processes based on $\mathrm{C}_{2}=$ - carbonylation shown in Figure 1 are commercially promising technologies for MMA manufacture. The $\mathrm{C}_{2}=$ carbonylation process consists of three steps: propionate synthesis, propionate condensation, and esterification.

While propionate synthesis is commercially practiced by Eastman Chemical (to manufacture propionic acid, propionic anyhydride, and methyl propionate) at their Kingsport, Tennessee facility, the process for condensation of these propionyls with formaldehyde to produce methacrylic acid (MAA) is less well developed.[Reactions (1) to (3) are the possible routes to MAA, Reactions (1) and (2) and MMA (Reaction (3))], via propionate condensation with formaldehyde. For (1) and (2), MAA is esterified with routes methanol to produce MMA in a subsequent step.

$$
\begin{aligned}
& \left(\mathrm{CH}_{3} \mathrm{CH}_{2} \mathrm{CO}\right)_{2} \mathrm{O}+\mathrm{HCHO} \rightarrow \mathrm{CH}_{2}=\mathrm{C}\left(\mathrm{CH}_{3}\right) \mathrm{COOH}+\mathrm{CH}_{3} \mathrm{CH}_{2} \mathrm{COOH} \\
& \mathrm{CH}_{3} \mathrm{CH}_{2} \mathrm{COOH}+\mathrm{HCHO} \rightarrow \mathrm{CH}_{2}=\mathrm{C}\left(\mathrm{CH}_{3}\right) \mathrm{COOH}+\mathrm{H}_{2} \mathrm{O} \\
& \mathrm{CH}_{3} \mathrm{CH}_{2} \mathrm{COOCH}+\mathrm{HCHO} \rightarrow \mathrm{CH}_{2}=\mathrm{C}\left(\mathrm{CH}_{3}\right) \mathrm{COOCH}+\mathrm{H}_{2} \mathrm{O}
\end{aligned}
$$

Condensation reactions are catalyzed by acid-base catalysts $[2,3]$. The relationship between the strength and density of these acid-base sites and the condensation reaction yields is unresolved. Typically, a condensation reaction between a propionate and formaldehyde involves catalytic sites which have a dual acid-base property [4,5]. Thus, the catalyst preparation testing and characterization work specifically focused on the acid-base properties of the condensation catalysts.

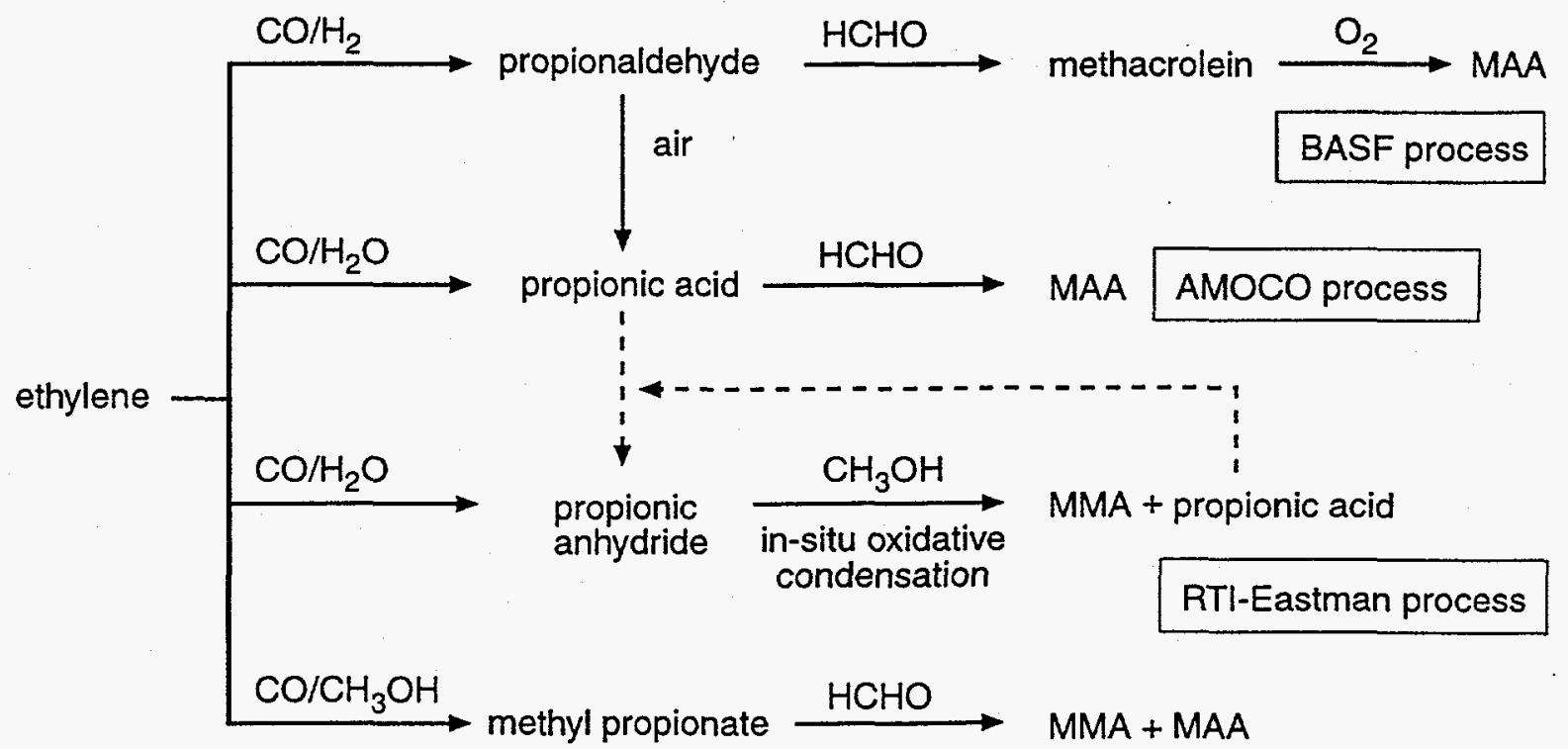

Fig. 1. $\mathrm{C}_{2}=$ - carbonylation technologies for MMA manufacture. 


\section{RESULTS AND DISCUSSION}

A key goal of this research is to find a stable and selective catalyst for the condensation of propionic acid and anhydride with formaldehyde. As stated earlier, both acid and base sites are needed for the condensation reaction to occur and a balance of acid-base strengths is needed for maximizing the condensation yields. The condensation of propionic acid and formaldehyde has been studied in several recent references [6-8]; however, the yield of MAA and the selectivity have been poor. As a feedstock for condensation, propionic anhydride has the advantage of producing one less mole of water, which simplifies the product slate for separation. The catalysts for condensation of propionic anhydride with formaldehyde have been reported in only one U.S. patent [9]. Based on our catalyst development and acid-base correlations, catalysts to condensation of the anhydride show extremely promising commercial prospect. The V-Si-P and $\mathrm{Ta}$-Si catalysts have been patented.

Over 45 acid-base catalysts were synthesized and tested in a fixed-bed microreactor system, for condensation of propionic anhydride with formaldehyde. Out of these 45 catalysts, a V-Si-P $(1: 12: 2.8)$ and a Ta-Si (1:10) gave the maximum yields. These catalysts were systematically studied further for the acid-base property correlation (see Table 1).

Two catalysts (V-Si-P 1:10:2.8 and Ta-Si 1:10) were chosen for a long-term deactivation study. The initial MAA yield was $55.8 \%$ (based on charged HCHO) for the V-Si-P catalyst. At the completion of the long-term activity experiment, MAA yield dropped to $2.74 \%$. The long-term deactivation pattern of the $\mathrm{V}-\mathrm{Si}-\mathrm{P}$ and $\mathrm{Ta}-\mathrm{Si}$ are shown in Figure 2 . The deactivated catalyst was treated at $300^{\circ} \mathrm{C}$, in a mildly oxidizing atmosphere, with $2 \%$ oxygen in nitrogen as the treatment

\section{TABLE 1}

Effect of catalyst acid-base properties on methacrylic acid yield ${ }^{2}$

\begin{tabular}{|c|c|c|c|c|c|c|c|}
\hline $\begin{array}{c}\text { Catalyst } \\
\text { (atomic } \\
\text { ratio) } \\
\end{array}$ & $\begin{array}{c}\text { Surface } \\
\text { area (bet- } \\
\mathrm{N}_{2}, \mathrm{~m}^{2} / \mathrm{g} \text { ) }\end{array}$ & $\begin{array}{l}\text { Total acidity } \\
(\mu \mathrm{mol} \\
\left.\left[\mathrm{NH}_{3}\right] / \mathrm{g} \text { cat }\right)\end{array}$ & $\begin{array}{l}\text { Total acidity } \\
(\mu \mathrm{mol} \\
\left.\mathrm{NH}_{3} / \mathrm{m}^{2} \text { cat }\right)\end{array}$ & $\begin{array}{c}\text { Total } \\
\text { basicity } \\
(\mu \mathrm{mol} \\
\left.\mathrm{CO}_{2} / \mathrm{g} \text { cat }\right)\end{array}$ & $\begin{array}{c}\text { Total } \\
\text { basicity } \\
(\mu \mathrm{mol} \\
\left.\mathrm{CO}_{2} / \mathrm{m}^{2}\right) \\
\end{array}$ & $\begin{array}{l}\text { MAA } \\
\text { yield }^{\text {b }}\end{array}$ & q-ratio \\
\hline $\begin{array}{l}\text { V-Si-P } \\
(1: 12-2.8)\end{array}$ & 96.5 & 155.7 & 1.61 & 100.2 & 1.04 & 52.7 & 0.39 \\
\hline $\begin{array}{l}\text { V-Si-P } \\
(1: 10: 2.8)\end{array}$ & 94.2 & 150.8 & 1.61 & 96.5 & 1.01 & 55.8 & 0.42 \\
\hline $\begin{array}{l}\text { V-Si-P } \\
(1: 3.57: 1)\end{array}$ & 114.2 & 174.9 & 1.53 & 59.1 & 0.51 & 38.9 & 0.27 \\
\hline $\begin{array}{l}\text { V-Si-P } \\
(1: 10: 10)\end{array}$ & 3.24 & 81.8 & 25.2 & 74.0 & 22.8 & 9.5 & 0.06 \\
\hline $\begin{array}{l}\text { Ta-Si } \\
(1: 10)\end{array}$ & 132.1 & 24.52 & 0.185 & 26.0 & 0.19 & 46.4 & 0.28 \\
\hline
\end{tabular}

${ }^{a}$ Reaction conditions: $\mathrm{T}=300{ }^{\circ} \mathrm{C}, \mathrm{P}=2$ atm ( 30 psi in-house nitrogen), mole flow rates of propionic anhydride:formaldehyde:nitrogen $=40(41$, actual): $20(17$, actual): $220 \mathrm{mmol} / \mathrm{h}$.

${ }^{\mathrm{MAA}}=$ methacrylic acid, yield based on charged $\mathrm{HCHO}$, i.e., mole $\mathrm{MMA} / \mathrm{mole}$ charged $\mathrm{HCHO} \times 100$. 


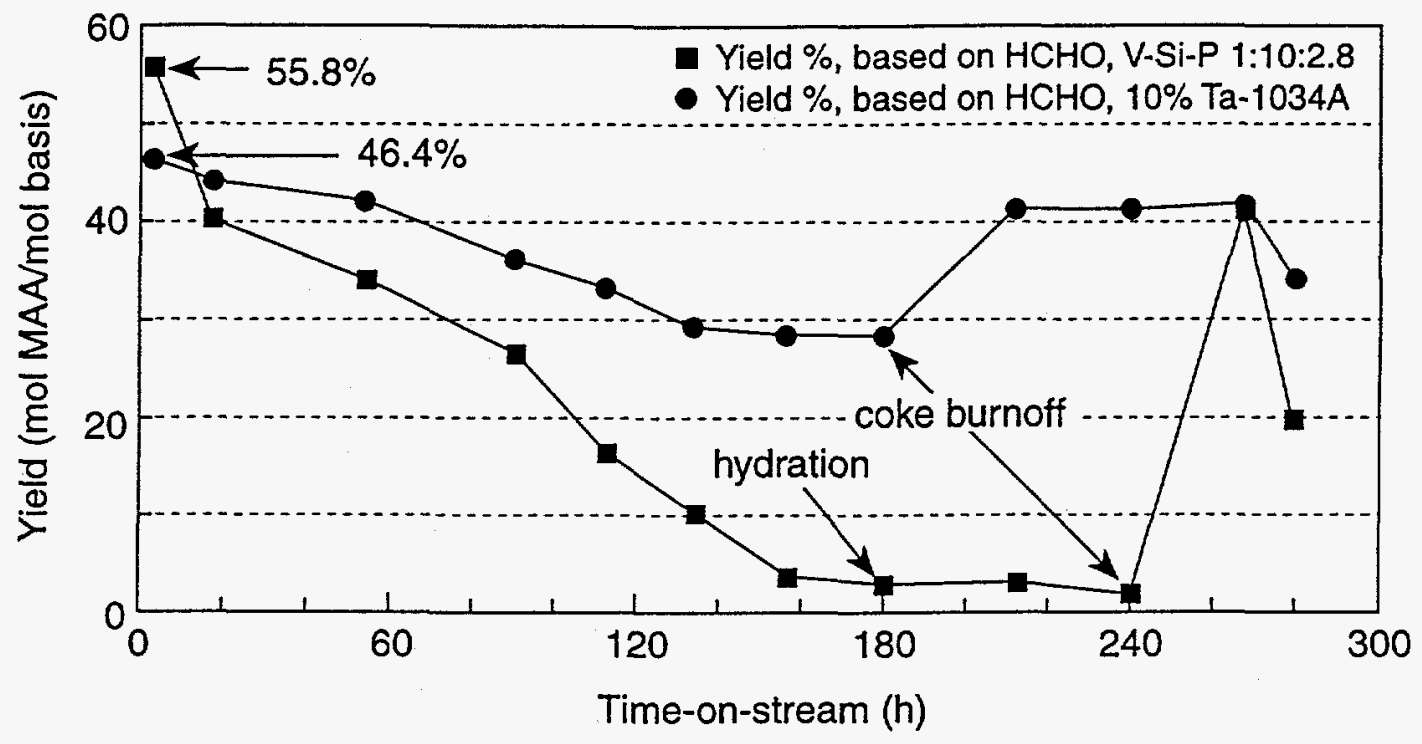

Fig. 2. Long-term deactivation of V-Si-P and Ta-Si catalysts.

gas. [Hydration of the surface did not restore activity.] The activity of the catalyst was checked following this regeneration. The methacrylic acid yield was restored to $40.8 \%$. This suggests that the deactivation was due to coke formation on the catalyst surface. The Ta-Si catalyst shows greater stability with time-on-stream than the V-Si-P catalyst (Figure 2) although the initial yields of MAA are similar for these two catalysts. Because the condensation reaction is catalyzed by the acid and base sites on the catalyst surface, these properties were measured using temperature-programmed desorption (TPD) of $\mathrm{NH}_{3}$ (for the acid sites) and $\mathrm{CQ}_{2}$ (for the base sites) [3-6]. To quantify the correlation between the catalyst acid/base properties, a new TPD parameter called the q-ratio was defined as [10]:

$$
q=A_{1} \text { (desorbed at } 50 \text { to } 300^{\circ} \mathrm{C} \text { ) } / A_{2} \text { (desorbed from } 50 \text { to } 550^{\circ} \mathrm{C} \text { ) }
$$

where, $A_{i}$ is the area under the TPD pattern. The q-ratios for the V-Si-P series of catalysts $(1: 12: 2.8,1: 10: 2.8$, and $1: 3.57: 1)$ are $0.39,0.42$, and 0.28 , respectively (Table 1$)$. The rapid deactivation of the V-Si-P catalyst may be caused by its stronger acidic surface, as shown by the higher q-ratio in Table 1. The q-ratio for the $10 \% \mathrm{Ta}-\mathrm{Nalco} \mathrm{SiO}_{2}$ catalyst is also high, at 0.28. At lower q-ratios, condensation yields are lower. The q-ratio for the V-Si-P (1:10:10) catalyst is 0.06 , and the MAA yield for this catalyst is $9.46 \%$. The surface acidity patterns for V-Si-P $(1: 10: 2.8,1: 10: 10)$ and Ta-Si catalysts have been compared in Figure 3. For the V-Si-P (1:10:10) catalyst, $94 \%$ of the acidity is the high-temperature region, which is counteractive to higher condensation yields. An activation energy calculation using the TPD data shows that the activation energy of the high-temperature peaks is approximately $25 \mathrm{kcal} / \mathrm{mol}$, suggesting that the strength of these sites is strongly temperature dependent. The effects of pretreatment time, temperature, and acid-base properties of fresh and deactivated catalysts indicate that thermal deactivation (by sintering or catalyst agglomeration) may also be responsible for accelerating coke formation. Because heat transfer in the laboratory fixed-bed reactors is considerably poorer than industrial type pilot-scale reactors, a slurry reactor is also better suited for these highly exothermic condensation reactions in industrial practice. 


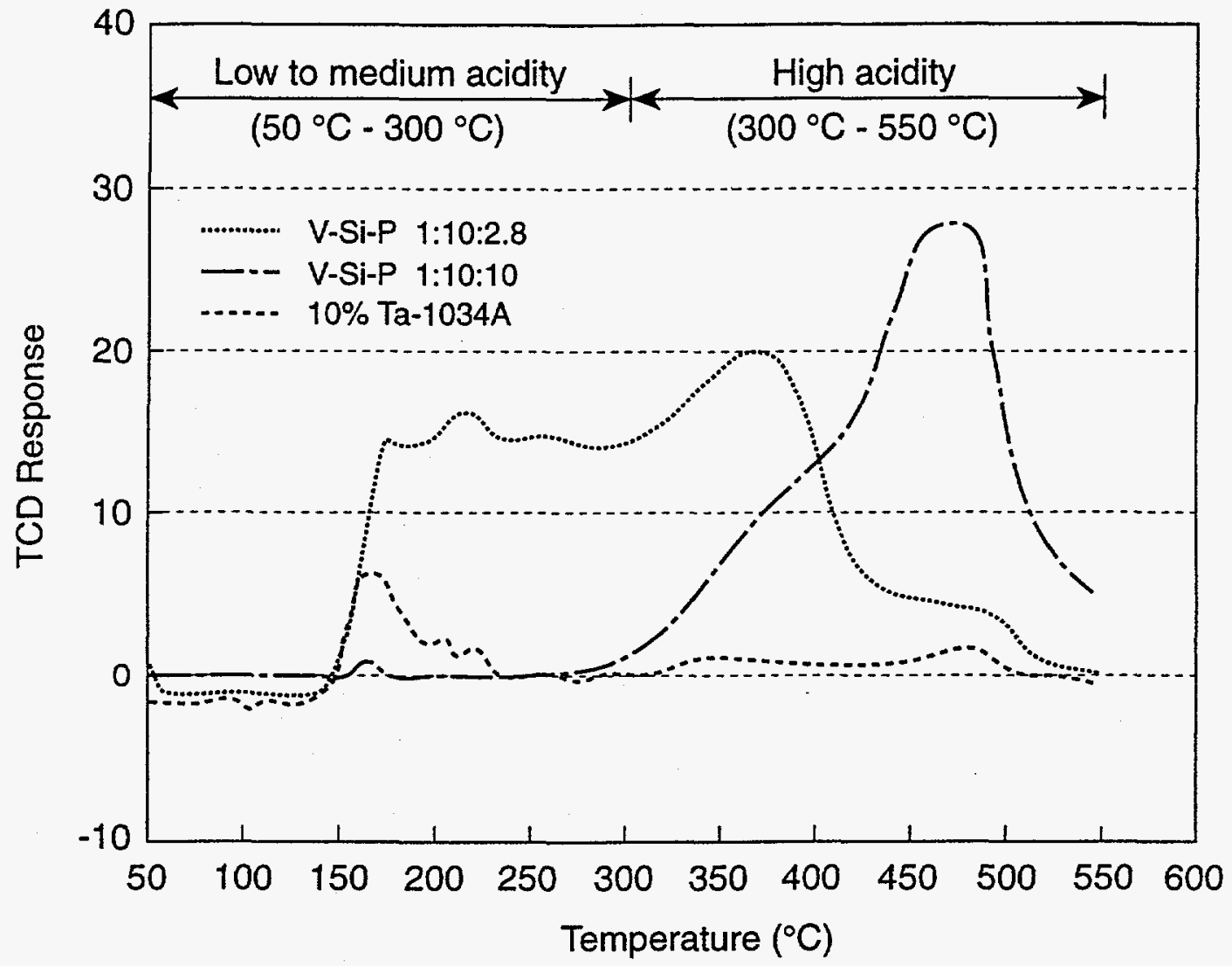

Fig. 3. Comparative surface acidity patterns of V-Si-P and Ta-Si catalysts.

\section{CONCLUSIONS}

Condensation Catalysis. Novel V-Si-P ternary catalysts and Ta-silica catalysts that exhibit higher condensation yields have characteristic low-temperature acid and base desorption peaks and an absence of high-temperature peak in the range of 300 to $550{ }^{\circ} \mathrm{C}$. Higher q-ratios correspond directly with higher condensation yields and magnitude of surface acidity in the lowstrength region impacts the long-term deactivation. The acid-base property suggests that a low overall surface acidity with a high q-ratio coupled with an effective reactor heat removal scheme may be best for a commercial catalyst. These relations are currently being exploited to design Phase II (more active, more stable) condensation catalysts.

\section{ACKNOWLEDGMENTS}

The authors gratefully acknowledge the support of this research by the U.S. Department of Energy, Pittsburgh Energy Technology Center, Project Officer Dick Tischer, and Eastman Chemical Company. 


\section{REFERENCES}

1. J.J. McKetta, Ed., Encyclopedia of Chemical Processing and Design, Vol. 30 (1989).

2. J.J. Spivey, M.R. Gogate, B.W.L. Jang, E.D. Middlemas, J.R. Zoeller, S.S. Tam, and G.N. Choi, Proceedings of Contractors' Review Meeting on Coal Liquifaction and Gas Conversion, pp. 385-395, USDOE/PETC, Pittsburgh, PA (1995).

3. J.J. Spivey, M.R. Gogate, B.W.L. Jang, E.D. Middlemas, J.R. Zoeller, S.S. Tam, and G.N. Choi, Invited Paper Presented at the Second Annual World Environmental Congress, London, Ontario, September 11-16, 1995.

4. M.R. Gogate, J.J. Spivey, and J.R. Zoeller, In Proceedings of the ACS National Meeting, Division of Petroleum Chemistry, Symposium on Syngas Conversion to High Value Chemicals. pp. 216-219. New Orleans, LA. (1996).

5. J.J. Spivey, M.R. Gogate, and J.R. Zoeller, In Proceedings of the ACS National Meeting, Division of Petroleum Chemistry, Symposium on Syngas Conversion to High Value Chemicals. pp. 233-237. New Orleans, LA. (1996).

6. M. Ai, Appl. Catal. 63:29 (1990).

7. O.H. Bailey, R.A. Montag, and J.S. Yoo, Appl. Catal. A:General 88:163. (1990).

8. J.S. Yoo, Appl. Catal. A: General 102:215 (1993).

9. J.D. Holmes, U.S. Patent 4,085,143 (1978).

10. T. Kanno, and M. Kobayashi, Ch. 2.14 in H. Hattori, M. Misono, and Y. Ono eds. AcidBase Catalysis II. Elsevier, Tokyo, Japan. (1994). 